\title{
A Group decision making problem using hierarchical based fuzzy soft matrix approach
}

\author{
Samsiah Abdul Razak ${ }^{1, *}$, Daud Mohamad ${ }^{2}$, Ini Imaina Abdullah ${ }^{1}$ \\ ${ }^{1}$ Faculty of Computer and Mathematical Sciences, Universiti Teknologi MARA, Perak Branch, Tapah Campus, 35400 Tapah Road, \\ Perak, Malaysia \\ ${ }^{2}$ Faculty of Computer and Mathematical Sciences, Universiti Teknologi MARA, Shah Alam, 40450 Shah Alam, Selangor, Malaysia
}

\section{A R T I C L E IN F O}

\section{Article history:}

Received 8 June 2017

Received in revised form

3 August 2017

Accepted 8 August 2017

Keywords:

Fuzzy soft sets

Fuzzy soft matrix

Fuzzy soft hierarchical

Lambda-max method

\begin{abstract}
A B S T R A C T
Fuzzy soft sets theory is a general mathematical tools to dealing with uncertainty problem. The matrix form has been introduced in fuzzy soft set and some of its properties have been discussed. However the theory of fuzzy soft set has been extensively used in many application, the importance weight of criteria has not been emphasized and thus is not incorporated in the calculation. The aim of this paper is to propose a selection procedure by group decision making in a hierarchical structure with fuzzy soft matrix. The lambda-max method is utilized in determining the criteria weight for the main and sub - criteria, while alternative decision will be solved by using fuzzy soft max-min decision making method. The hierarchical structure in Fuzzy AHP concept is applied to determine the overall priority vector, where the highest score is the desired alternative.
\end{abstract}

(C) 2017 The Authors. Published by IASE. This is an open access article under the CC BY-NC-ND license (http://creativecommons.org/licenses/by-nc-nd/4.0/).

\section{Introduction}

Various decision making models have been introduced to solve various type decision making problems. According to Carlsson and Fullér (1996) the models can be categorized into three, which the Multicriteria decision is making (MCDM), Multiattribute decision making (MADM) and Multi Objective Decision Making (MODM). In some situations, the problems are better represented in hierarchical structure and one of the best suited methods to be used is the Analytic Hierarchy Process (AHP), a method in MCDM. A hierarchy is basically can be viewed as a stratified system for organizing objects. In other words, it helps to locate and group objects effectively. The hierarchical structure has its own advantage as it gives an overall picture of the complex relationship inherent in the situation and assists the decision makers to address the issue in each level.

Soft set theory was first introduced by Molodtsov (1999). It's known as general mathematical tools to deal with the complexities of modelling uncertain data. Its parameterized representation is useful and convenient to apply to many decision making

\footnotetext{
* Corresponding Author.

Email Address: samsiah179@perak.uitm.edu.my (S. A. Razak) https://doi.org/10.21833/ijaas.2017.010.005

2313-626X/C) 2017 The Authors. Published by IASE.

This is an open access article under the CC BY-NC-ND license

(http://creativecommons.org/licenses/by-nc-nd/4.0/)
}

situations. At present, the investigation on the soft set theory is progressing rapidly and has been successfully applied in many different fields (Molodtsov; 1999; Maji et al., 2002; Herawan and Deris; 2010). Çağman and Enginoğlu (2010a; 2010b) redefined the operation of soft set and introduced uni-int decision making and four products of soft sets. As a generalization the standard concept of soft sets, Maji et al. (2001) introduced fuzzy soft theory and applied it to decision making problems.

Some researchers applied fuzzy soft sets in theoretical and practical applications of decision making problems (Roy and Maji, 2007; Chetia and Das, 2010; Maji et al., 2002). Çağman and Enginoğlu (2010a; 2010b) presented soft matrix theory and introduced the soft max-min decision making to solve a decision making problem with two decision makers. Wei (2010) proposed the method of fuzzy soft matrices (FSM), defined the basic concept and discussed some other properties of FSM. Later, Yang and Ji (2011) defined the fuzzy soft matrices and also discussed the properties of FSM and in particular the commutative law in soft matrices used in Çağman and Enginoğlu (2010a; 2010b). They showed the validity of the commutative law in their concept. Celik and Celik (2016) applied fuzzy soft matrices approach for medical diagnosis in hypothetical case study.

Çağman and Enginoğlu (2012) proposed a softmax min decision making method. Later Razak and Mohamad (2012) extended the model of Soft matrix 
and fuzzy soft matrix in group decision making problems.

Observing the strength of both mathematical tools of AHP and fuzzy soft sets, in this paper we consider the group decision making problem that convert the complex problem into hierarchical structure and solve by using fuzzy soft max-min decision making method (FSMmDM) incorporating together with weight of criteria determined by using Lambda-max approach by Csutora and Buckley (2001) and the result is calculated based on score of overall priority vector using the concept of AHP (Hambali et al., 2009).

\section{Preliminaries}

The following are some basic definitions that will be used in this paper.

\subsection{Fuzzy soft sets}

The following definition is taken from Çağman and Enginoğlu (2012).

Definition 2.1.1: Let $U$ be an initial universe set and $E$ be a set of all parameters. Let $F(U)$ denotes the set of all fuzzy sets $\operatorname{in} U$. Then $(\widetilde{F}, A)$ is called a fuzzy soft set over $U$ where $A \subset C$ and $\tilde{F}$ is a mapping given $\operatorname{by}(\widetilde{F}: A \rightarrow F(U))$.

In general, for every $x \in A, \tilde{F},[x]$ is a fuzzy set in $U$ and it is called fuzzy value set of parameter $x$. If for every $x \in A, \tilde{F},[x]$ is a crisp subset of $U$, then $(F, A)$ is degenerated to be the standard soft set.

\subsection{Fuzzy soft matrix}

The following definition is taken from Yang and Ji (2011) in introducing fuzzy soft decision making method.

Definition 2.2.1: Let $(\widetilde{F}, A)$ be a fuzzy soft set over $U$, where $U=\left\{u_{1}, u_{2}, \cdots u_{m}\right\}$ be an initial universe set,
$E=\left\{e_{1}, e_{2}, \cdots e_{n}\right\}$ be a set of parameters and $A \subseteq E$. For $\forall u_{i} \in U$ and $\forall e_{i} \in E$, there exists membership degree, $\left[a_{i j}\right]=f_{e j}\left(u_{i}\right)$ then all the membership degrees will be presented by a Table 1 as follows:

Table 1: Evaluation of membership degree of FSM

\begin{tabular}{ccccc}
\hline & $\mathrm{e}_{1}$ & $\mathrm{e}_{2}$ & $\cdots$ & $\mathrm{e}_{\mathrm{mn}}$ \\
$\mathrm{u}_{1}$ & $a_{11}$ & $a_{12}$ & $\ldots$ & $\mathrm{a}_{1 \mathrm{n}}$ \\
$\mathrm{u}_{2}$ & $a_{21}$ & $a_{22}$ & $\ldots$ & $\mathrm{a}_{2 \mathrm{n}}$ \\
$\vdots$ & $\vdots$ & $\vdots$ & $\ddots$ & $\vdots$ \\
$\mathrm{u}_{\mathrm{m}}$ & $\mathrm{u}_{\mathrm{m} 1}$ & $\mathrm{u}_{\mathrm{m} 2}$ & $\ldots$ & $\mathrm{u}_{\mathrm{mn}}$ \\
\hline
\end{tabular}

The matrix

$$
A_{m \times n}=\left[a_{i j}\right]_{m \times n}=\left(\begin{array}{cccc}
a_{11} & a_{12} & \cdots & a_{1 n} \\
a_{21} & a_{22} & \cdots & a_{2 n} \\
\vdots & \vdots & \ddots & \vdots \\
a_{m 1} & a_{m 2} & \cdots & a_{m n}
\end{array}\right)
$$

is called Fuzzy Soft Matrix.

\section{Hierarchical based procedure}

Our proposed procedure for solving decision making problems consists of three main components:

\subsection{Criteria weight determination using lambda- max method}

The Lambda-max method by Csutora and Buckley (2001) is one of the fuzzy AHP approaches used to determine criteria weight of decision making when the comparison is made in pairwise. In contrary to some other methods of weight determination that offer the weight in crisp values, the Lambda-max method presents the criteria weight in fuzzy form. This will ensure that the information is lost due to simplification. The procedure of the Lambda - max method can be obtained in Csutora and Buckley (2001).

In determination criteria weight we use the following linguistic variables and its membership function is shown in Table 2.

Table 2: Triangular fuzzy conversion center

\begin{tabular}{|c|c|c|c|}
\hline Degree of Importance & $\begin{array}{l}\text { Linguistic variable } \\
\text { Equally preferred }\end{array}$ & $\begin{array}{c}\text { Triangular Fuzzy Scale } \\
(1,1,1)\end{array}$ & $\begin{array}{c}\text { Triangular Fuzzy Reciprocal Scale } \\
(1,1,1)\end{array}$ \\
\hline$\tilde{2}$ & Equally to moderate preferred & $(1,2,4)$ & $(1 / 4,1 / 2,1)$ \\
\hline$\tilde{3}$ & Moderately preferred & $(1,3,5)$ & $(1 / 5,1 / 3,1)$ \\
\hline$\tilde{4}$ & Moderately to strongly preferred & $(2,4,6)$ & $(1 / 6,1 / 4,1 / 2)$ \\
\hline$\tilde{5}$ & Strongly preferred & $(3,5,7)$ & $(1 / 7,1 / 5,1 / 3)$ \\
\hline$\tilde{6}$ & Strongly to very Strongly preferred & $(4,6,8)$ & $(1 / 8,1 / 6,1 / 4)$ \\
\hline$\tilde{7}$ & Very strong preferred & $(5,7,9)$ & $(1 / 9,1 / 7,1 / 5)$ \\
\hline$\tilde{8}$ & Very to extremely preferred & $(6,8,9)$ & $(1 / 9,1 / 8,1 / 6)$ \\
\hline$\tilde{9}$ & Extremely preferred & $(7,9,9)$ & $(1 / 9,1 / 9,1 / 7)$ \\
\hline
\end{tabular}

\subsection{Fuzzy soft max-min decision making method}

FSMmDM method introduced by Çağman and Enginoğlu (2012) to solve decision making problem that involved two decision makers. They defined the And-product, the fuzzy soft max-min decision function and give the fuzzy soft max-min decision making (FSMmDM) algorithm as follows.
Definition 3.2.1: Let $\left[r_{i j}\right],\left[s_{i k}\right] \in S M_{m \times n}$ where $S M_{m \times n}$ is the soft matrix of dimension $(m \times n)$. The And - product between $\left[r_{i j}\right]$ and $\left[s_{i k}\right]$ is defined by

$\wedge: S M_{m \times n} \times S M_{m \times n} \rightarrow S M_{m \times n^{2}},\left[r_{i j}\right] \wedge\left[s_{i k}\right]=\left[t_{i p}\right]$ where $\left[t_{i p}=\min \left\{r_{i j}, s_{i k}\right\}\right]$ such that $p=(n+1)+k$.

Definition 3.2.2: Let 
$\left[c_{i p}\right] \in F S M_{m \times n^{2}}, I_{k}=\left\{p: \exists i, c_{i p} \neq 0,(k-1) n\right\}, p \leq k n$

for all $k \in I=\{1,2, \cdots n\}$ where $F S M_{m \times n^{2}}$ is the fuzzy soft matrix of dimension $m \times n^{2}$. Then fuzzy soft $(f s)$ max-min decision function, denoted $M m$, is defined as follows:

$M_{m: F S M}: M_{m \times n^{2}} \rightarrow F S M_{m \times n^{1}}$

$\operatorname{Mm}\left[c_{i p}\right]=\left[d_{i l}\right]=\left[\begin{array}{l}\max \\ k \in I\end{array}\left\{t_{i k}\right\}\right]$

where,

$t_{i k}=\left\{\begin{array}{cc}\min \left\{c_{i p}\right\} & \text { ifI } I_{k} \neq \varnothing \\ p_{e} I_{k} & \\ 0, & \text { ifI } I_{k} \neq \varnothing\end{array}\right\} ;$

the one column $f s$-matrix $M m\left(c_{i p}\right)$ is called max-min decision fuzzy soft matrix.

Definition 3.2.3: Let $=\left\{u_{1}, u_{2}, \cdots u_{m}\right\}$ be an initial universe and $M m\left[c_{i p}\right]=\left[d_{i l}\right]$. Then a subset of $U$ can be obtained by using $\left[d_{i l}\right]$ as in the following expression $O p t\left[d_{i l}\right](u)=\left\{d_{i l} / u_{i}: u_{i} \in U\right\}, d_{i l} \neq 0$, which is called an optimum fuzzy set of $U$.

Now, by using Definition 3.2.2 and 3.2.3 the FSMmDM algorithm is given as follow:

Step 1: Choose the feasible subsets of the set of parameters.

Step 2: Use the matrix form to construct the $f s$ matrix for each set of parameters.

Step 3: Find the And-product for the $f s$-matrices.

Step 4: Find a max-min decision $f_{S}$-matrix.

Step 5: Find an optimum set of $\mathrm{U}$

\subsection{Fuzzy soft max-min decision making method (FSMmDM) with criteria weight}

Razak and Mohamad (2012) generalized the method of Çağman and Enginoğlu (2012) to $\mathrm{n}^{\text {th }}$ number of decision makers using FSMmDM approach that satisfied the associative law and employed together with the weight of each criteria and sub-criteria. The FSMmDM method procedure together with weight is constructed as follows:

- Step B1: Evaluate the membership value of alternatives with respect to sub-criteria in decision making problems.

- Step B2: Use matrix form to construct the fuzzy soft matrices for each set sub-criteria according to its main criteria.

$\left[D M_{R i j}^{k}\right]_{m \times n}=\left[\begin{array}{cccc}a_{11} & a_{12} & \cdots & a_{1 n} \\ a_{21} & a_{22} & \cdots & a_{2 n} \\ \vdots & \vdots & \ddots & \vdots \\ a_{m 1} & a_{m 2} & \cdots & a_{m n}\end{array}\right]$

where, $m$ is the number of indicators involved and $n$ is the number of sub - criteria with respect to criteria $N$.

- Step B3: Incorporate importance weight of subcriteria $\widehat{W}_{N j}$ and compute the values for each alternative. Then construct the fuzzy soft matrices,
$\widehat{W}_{N j}=\left(\widehat{w}_{N 1}, \widehat{w}_{N 2}, \cdots \widehat{w}_{N n}\right)$

is the importance weight of sub-criteria with respect to criteria $N$, where

$j=(1,2, \cdots n)$. Hence $\left[D \widehat{M}_{i j}^{\times} \times \widehat{W}_{N j}\right]_{m \times n}$

$D \widehat{M}_{N}^{k}=\left[D \widehat{M}_{i j}^{k} \times \widehat{W}_{N j}\right]_{m \times n}=$

$\left[\begin{array}{cccc}a_{11} \otimes \widehat{w}_{N_{1}} & a_{12} \otimes \widehat{w}_{N_{2}} & \cdots & a_{1 n} \otimes \widehat{w}_{N_{n}} \\ a_{21 \otimes \widehat{w}_{N_{1}}} & a_{22} \otimes \widehat{w}_{N_{2}} & \cdots & a_{2 n} \otimes \widehat{w}_{N_{n}} \\ \vdots & \vdots & \ddots & \vdots \\ a_{m 1 \otimes \widehat{w}_{N_{1}}} & a_{m 2} \otimes \widehat{w}_{N_{2}} & \cdots & a_{m n} \otimes \widehat{w}_{N_{n}}\end{array}\right] ;$

where $D \widehat{M}_{N}^{k}$ is fuzzy soft matrix with sub-criteria weight with respect to criteria $N$ for decision maker $k$.

- Step B4: Find the And-product of fuzzy soft matrices

(e.g. $\left.\left(D M_{n-1} \wedge D M_{n}\right)=A\right)$

$\left[D \widehat{M}_{N}^{1}\right] \wedge\left[D \widehat{M}_{N}^{2}\right]=\min \left(d \widehat{m}_{N}^{1} \wedge d \widehat{m}_{N}^{2}\right)$

$\left[D \widetilde{M}_{N}^{1}\right] \wedge\left[D \widetilde{M}_{N}^{2}\right]=\left[\begin{array}{cccc}d \widetilde{m}_{N_{11}}^{1} & d \widetilde{m}_{N_{12}}^{1} & \cdots & d \widetilde{m}_{N_{1 n}}^{1} \\ d \widetilde{m}_{N_{21}}^{1} & d \widetilde{m}_{N_{22}}^{1} & \cdots & d \widetilde{m}_{N_{2 n}}^{1} \\ \vdots & \vdots & \ddots & \vdots \\ d \widetilde{m}_{N_{m 1}}^{1} & d \widetilde{m}_{N_{m 2}}^{1} & \cdots & d \widetilde{m}_{N_{m n}}^{1}\end{array}\right] \wedge$

$\left[\begin{array}{cccc}d \widetilde{m}_{N_{11}}^{2} & d \widetilde{m}_{N_{12}}^{2} & \cdots & d \widetilde{m}_{N_{1 n}}^{2} \\ d \widetilde{m}_{N_{21}}^{2} & d \widetilde{m}_{N_{22}}^{2} & \cdots & d \widetilde{m}_{N_{2 n}}^{2} \\ \vdots & \vdots & \ddots & \vdots \\ d \widetilde{m}_{N 1}^{2} & d \widetilde{m}_{N_{m 2}}^{2} & \cdots & d \widetilde{m}_{N_{m n}}^{2}\end{array}\right]$

In this step, we can be obtained $\left(m \times n^{2}\right)$ of fuzzysoft matrix, in which there are $\mathrm{n}$ blocks of $(m \times n)$ elements in the above matrix.

- Step B5: Find the minimum of And-product

Between $\left[D \widehat{M}_{N}^{1}\right]$ and $\left[D \widehat{M}_{N}^{2}\right]$, for each $\mathrm{n}$ blocks of elements above.

$\min \left[D M_{N}^{1} \wedge D M_{N}^{2}\right]=[\hat{A}]=\left[\begin{array}{cccc}\hat{a}_{11} & \hat{a}_{12} & \cdots & \hat{a}_{1 n} \\ \hat{a}_{21} & \hat{a}_{22} & \cdots & \hat{a}_{2 n} \\ \vdots & \vdots & \ddots & \vdots \\ \hat{a}_{m 1} & \hat{a}_{m 2} & \cdots & \hat{a}_{m n}\end{array}\right]$

where

$\hat{a}_{m n}=\min \left[D M_{N}^{1} \wedge D M_{N}^{2}\right]$

- Step B6: Find the And-product between Âand $\left[D M_{N}^{3}\right]$

$\min \left[\hat{A} \wedge D M_{N}^{2}\right]=[\hat{B}]=\left[\begin{array}{cccc}\hat{a}_{11} & \hat{a}_{12} & \cdots & \hat{a}_{1 n} \\ \hat{a}_{21} & \hat{a}_{22} & \cdots & \hat{a}_{2 n} \\ \vdots & \vdots & \ddots & \vdots \\ \hat{a}_{m 1} & \hat{a}_{m 2} & \cdots & \hat{a}_{m n}\end{array}\right] \wedge$

$\left[\begin{array}{cccc}d \widetilde{m}_{N_{11}}^{3} & d \widetilde{m}_{N_{12}}^{3} & \cdots & d \widetilde{m}_{N_{1 n}}^{3} \\ d \widetilde{m}_{N_{21}}^{3} & d \widetilde{m}_{N_{22}}^{3} & \cdots & d \widetilde{m}_{N_{2 n}}^{3} \\ \vdots & \vdots & \ddots & \vdots \\ d \widetilde{m}_{N_{m 1}}^{3} & d \widetilde{m}_{N_{m 2}}^{3} & \cdots & d \widetilde{m}_{N_{m n}}^{3}\end{array}\right] ;$

we can be obtained $\left(m \times n^{2}\right)$ of fuzzy soft matrix, in which there are $\mathrm{n}$ blocks of $(m \times n)$ elements in the above matrix. Repeat step B5 to find the minimum of 
$\left[D M_{N}^{1}\right]$ and $\left[D M_{N}^{2}\right]$ for each $\mathrm{n}$ blocks of $(m \times$ $n$ )elements.

$\min \left[\hat{A} \wedge D M_{N}^{3}\right]=[\hat{B}]=\left[\begin{array}{cccc}\hat{b}_{11} & \hat{b}_{12} & \cdots & \hat{b}_{1 n} \\ b_{21} & \hat{b}_{22} & \cdots & \hat{b}_{2 n} \\ \vdots & \vdots & \ddots & \vdots \\ \hat{b}_{m 1} & \hat{b}_{m 2} & \cdots & \hat{b}_{m n}\end{array}\right]$,

where

$\hat{a}_{m n}=\min \left[\hat{A} \wedge D M_{N}^{3}\right]$

- Step B7: Find the max-min decision fuzzy soft matrix

$M m\left(\left[D M_{N}^{1} \wedge D M_{N}^{2}\right] \wedge\left[D M_{N}^{3}\right]\right)_{m \times 1}=\left[u_{1}, u_{2}, \cdots u_{n}\right]$

\subsection{Overall priority vector}

The concept of hierarchical structure of Fuzzy AHP by Razak and Mohamad (2012) is apply to calculate the overall priority vector at all level involved in the hierarchical level. The value in procedure one and procedure two will be combined together to determine the best selection of indicators. The step is discussed as follows:

- Step C1: Develop the framework of overall hierarchical

- level to find an overall priority vector.

- Step C2: Perform all levels in the hierarchical structure to get the overall priority vector as shown in Table 3.
An example of the overall priority calculation is as follow:

$=\left(u_{11} \times w_{m c 1}\right)+\left(u_{12} \times w_{m c 2}\right)+\cdots+\left(u_{1 N} \times w_{m c N}\right)$

where $u_{n N}{ }^{*}$ is decision alternatives in sub-criteria, $W_{m c N}$ is the importance weight of main criteria $N$.

- Step C3: As a result the highest score value of the overall priority vector will be chosen.

Table 3: Overall priority vector for the alternative with respect to the criteria

\begin{tabular}{ccccc}
\hline Alternative & $\begin{array}{c}\text { Main } \\
\text { Criteria } \\
1 m c_{1}\end{array}$ & $\begin{array}{c}\text { Main } \\
\text { Criteria } \\
2 m c_{2}\end{array}$ & $\begin{array}{c}\text { Main } \\
\text { Criteria } \\
\mathrm{Nm} c_{N}\end{array}$ & $\begin{array}{c}\text { Overall } \\
\text { Priority }\end{array}$ \\
\hline $\begin{array}{c}\text { Main criteria } \\
\text { weigh }\end{array}$ & $w_{m c 1}$ & $w_{m c 2}$ & $w_{m c N}$ & - \\
$u_{1}$ & $u_{11}$ & $u_{12}$ & $u_{1 N}$ & $u_{1}{ }^{*}$ \\
$u_{2}$ & $u_{21}$ & $u_{22}$ & $u_{2 N}$ & $u_{2}{ }^{*}$ \\
$\vdots$ & $\ddots$ & $\ddots$ & $\ddots$ & $\vdots$ \\
$u_{n}$ & $u_{n 1}$ & $u_{n 2}$ & $u_{n N}$ & $u_{n N}{ }^{*}$ \\
\hline
\end{tabular}

\section{Case study: house selection problem}

In this paper we convert the complex problem of house selection criteria in Razak and Mohamad (2012) into hierarchical structure. There are three main criteria, follow by nine sub-criteria and three expert group $\mathrm{A}, \mathrm{B}$ and $\mathrm{C}$ are consider as a decision maker to evaluate the house selection problem. The framework will be described in the following diagram in Fig. 1.

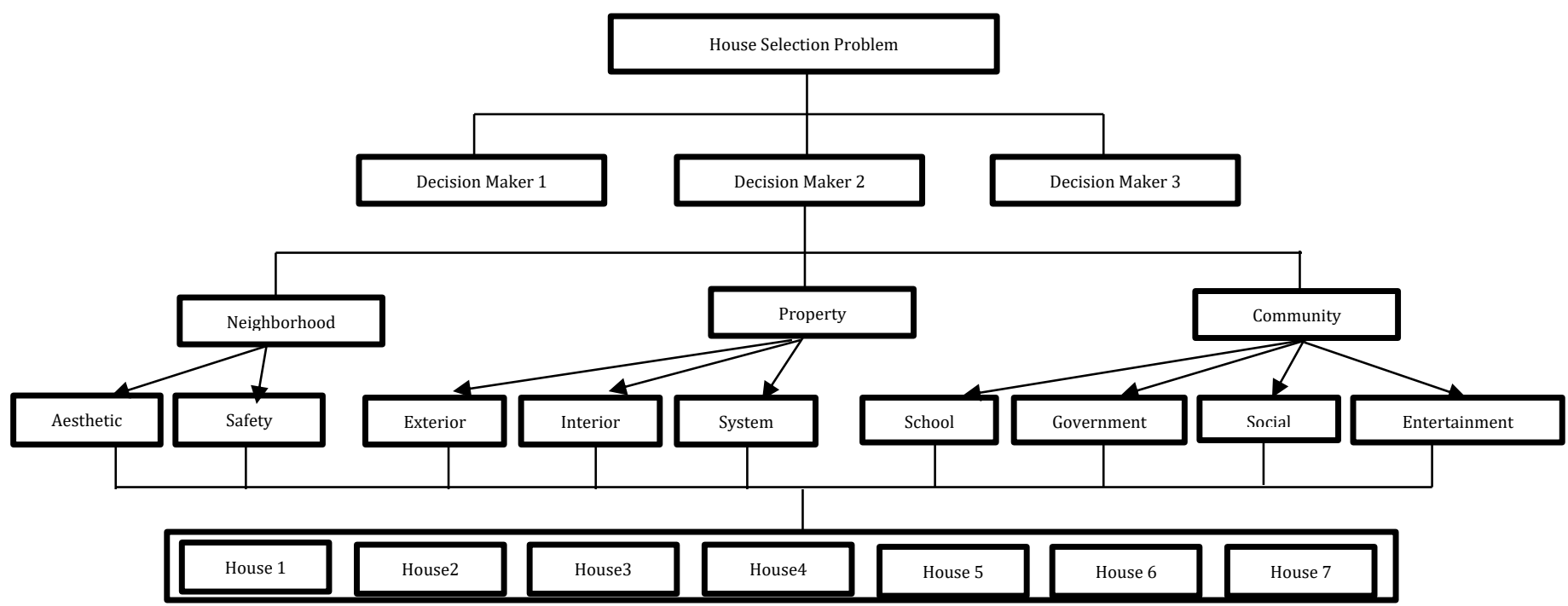

Fig. 1: Hierarchical structure of house selection problem

\subsection{House selection problem}

A soft set $\left(f_{A, E}\right)$ describes the "attractiveness of houses". Let $U=\left\{h_{1}, h_{2}, h_{3}, h_{4}, h_{5}, h_{6}, h_{7}\right\}$ be a goal set is a universe set consisting of six houses as possible alternatives, $M=\left\{m_{1}, m_{2}, m_{3}\right\}$ be a set of main criteria where $m_{1}, m_{2}, m_{3}$ represent the criteria "neighborhood", "property" and "community" respectively, and $E=\left\{e_{1}, e_{2}, e_{3}, e_{4}, e_{5}, e_{6}, e_{7}, e_{8}, e_{9}\right\}$ is a set of sub-criteria , where $e_{1}, e_{2}, e_{3}, e_{4}, e_{5}, e_{6}, e_{7}, e_{8}$ and $e_{9}$ represent the parameters "aesthetic", "safety", "exterior", "interior", "system", "school", "government", "social" and "entertainment" respectively.

\subsection{Constructing the pair-wise comparison}

The fuzzy evaluation matrix relevant to goal for each main criteria and sub-criteria according to decision maker $A, B$ and $C$ are constructed via pair 
wise comparison using nine scales in Table 1 are shown in Tables 4-7.

Table 4: Fuzzy comparison matrix with respect to goal

\begin{tabular}{cccccccccc}
\hline $\mathrm{M}$ & & $\mathrm{m}_{1}$ & \multicolumn{5}{c}{$\mathrm{m}_{2}$} & \multicolumn{3}{c}{$\mathrm{m}_{3}$} & \\
\hline $\mathrm{DM}$ & $\mathrm{DM} 1$ & DM2 & DM3 & DM1 & DM2 & DM3 & DM1 & DM2 & DM3 \\
\hline $\mathrm{m}_{1}$ & $(1,1,1)$ & $(1,1,1)$ & $(1,1,1)$ & $(3,5,7)$ & $\left(\frac{1}{6}, \frac{1}{4}, \frac{1}{2}\right)$ & $\left(\frac{1}{5}, \frac{1}{3}, 1\right)$ & $(3,5,7)$ & $(1,1,1)$ & $\left(\frac{1}{7}, \frac{1}{5}, \frac{1}{3}\right)$ \\
$\mathrm{m}_{2}$ & $\left(\frac{1}{7}, \frac{1}{5}, \frac{1}{3}\right)$ & $(2,4,6)$ & $(1,3,5)$ & $(1,1,1)$ & $(1,1,1)$ & $(1,1,1)$ & $(2,4,6)$ & $(1,3,5)$ & $\left(\frac{1}{5}, \frac{1}{3}, 1\right)$ \\
$\mathrm{m}_{3}$ & $\left(\frac{1}{7}, \frac{1}{5}, \frac{1}{3}\right)$ & $(1,1,1)$ & $(3,5,7)$ & $\left(\frac{1}{6}, \frac{1}{4}, \frac{1}{2}\right)$ & $\left(\frac{1}{5}, \frac{1}{3}, 1\right)$ & $(1,3,5)$ & $(1,1,1)$ & $(1,1,1)$ & $(1,1,1)$ \\
\hline
\end{tabular}

Table 5: Fuzzy comparison matrix of two sub-criteria with respect to neighbourhood

\begin{tabular}{ccccccc}
\hline $\mathrm{E}$ & \multicolumn{3}{c}{$\mathrm{e}_{1}$} & \multicolumn{3}{c}{$\mathrm{e}_{2}$} \\
\hline $\mathrm{DM}$ & $\mathrm{DM} 1$ & DM2 & DM3 & DM1 & DM2 & DM3 \\
\hline $\mathrm{e}_{1}$ & $(1,1,1)$ & $(1,1,1)$ & $(1,1,1)$ & $\left(\frac{1}{9}, \frac{1}{7}, \frac{1}{5}\right)$ & $(3,5,7)$ & $\left(\frac{1}{8}, \frac{1}{6}, \frac{1}{4}\right)$ \\
$\mathrm{e}_{2}$ & $(5,7,9)$ & $\left(\frac{1}{7}, \frac{1}{5}, \frac{1}{3}\right)$ & $(4,6,8)$ & $(1,1,1)$ & $(1,1,1)$ & $(1,1,1)$ \\
\hline
\end{tabular}

Table 6: Fuzzy comparison matrix of three sub-criteria with respect to property

\begin{tabular}{cccccccccc}
\hline $\mathrm{E}$ & \multicolumn{1}{c}{$\mathrm{e}_{3}$} & & \multicolumn{3}{c}{$\mathrm{e}_{4}$} & & $\mathrm{e}_{5}$ & \\
\hline $\mathrm{DM}$ & DM1 & DM2 & DM3 & DM1 & DM2 & DM3 & DM1 & DM2 & DM3 \\
\hline $\mathrm{e}_{3}$ & $(1,1,1)$ & $(1,1,1)$ & $(1,1,1)$ & $\left(\frac{1}{7}, \frac{1}{5}, \frac{1}{3}\right)$ & $\left(\frac{1}{9}, \frac{1}{7}, \frac{1}{5}\right)$ & $(3,5,7)$ & $(1,3,5)$ & $\left(\frac{1}{7}, \frac{1}{5}, \frac{1}{3}\right)$ & $(5,7,9)$ \\
$\mathrm{e}_{4}$ & $(3,5,7)$ & $(5,7,9)$ & $\left(\frac{1}{7}, \frac{1}{5}, \frac{1}{3}\right)$ & $(1,1,1)$ & $(1,1,1)$ & $(1,1,1)$ & $(1,3,5)$ & $\left(\frac{1}{6}, \frac{1}{4}, \frac{1}{2}\right)$ & $\left(\frac{1}{7}, \frac{1}{5}, \frac{1}{3}\right)$ \\
$\mathrm{e}_{5}$ & $\left(\frac{1}{5}, \frac{1}{3}, 1\right)$ & $(3,5,7)$ & $\left(\frac{1}{9}, \frac{1}{7}, \frac{1}{5}\right)$ & $\left(\frac{1}{5}, \frac{1}{3}, 1\right)$ & $(2,4,6)$ & $(3,5,7)$ & $(1,1,1)$ & $(1,1,1)$ & $(1,1,1)$ \\
\hline
\end{tabular}

Table 7: Fuzzy comparison matrix of four sub-criteria with respect to community

\begin{tabular}{|c|c|c|c|c|c|c|c|c|c|c|c|c|}
\hline$E$ & & $\mathrm{e}_{6}$ & & & $\mathrm{e}_{7}$ & & & $\mathrm{e}_{8}$ & & & $e_{9}$ & \\
\hline $\begin{array}{l}\mathrm{D} \\
\mathrm{M}\end{array}$ & DM1 & DM2 & DM3 & DM1 & DM2 & DM3 & DM1 & DM2 & DM3 & DM1 & DM2 & DM3 \\
\hline $\mathrm{e}_{6}$ & $(1,1,1)$ & $(1,1,1)$ & $(1,1,1)$ & $(3,5,7)$ & $\left(\frac{1}{7}, \frac{1}{5}, \frac{1}{3}\right)$ & $\left(\frac{1}{7}, \frac{1}{7}, \frac{1}{5}\right)$ & $\left(\frac{1}{8}, \frac{1}{6}, \frac{1}{4}\right)$ & $(2,4,6)$ & $(1,2,4)$ & $(3,5,7)$ & $\left(\frac{1}{9}, \frac{1}{6}, \frac{1}{8}\right)$ & $\left(\frac{1}{8}, \frac{1}{6}, \frac{1}{4}\right)$ \\
\hline $\mathrm{e}_{7}$ & $\left(\frac{1}{7}, \frac{1}{5}, \frac{1}{3}\right)$ & $(3,5,7)$ & $(5,7,9)$ & $(1,1,1)$ & $(1,1,1)$ & $(1,1,1)$ & $(6,8,9)$ & $\left(\frac{1}{5}, \frac{1}{3}, 1\right)$ & $\left(\frac{1}{7}, \frac{1}{5}, \frac{1}{3}\right)$ & $\left(\frac{1}{9}, \frac{1}{7}, \frac{1}{5}\right)$ & $(3,5,7)$ & $(3,5,7)$ \\
\hline $\mathrm{e}_{8}$ & $(4,6,8)$ & $\left(\frac{1}{6}, \frac{1}{4}, \frac{1}{2}\right)$ & $\left(\frac{1}{4}, \frac{1}{2}, 1\right)$ & $\left(\frac{1}{9}, \frac{1}{8}, \frac{1}{6}\right)$ & $(1,3,5)$ & $(3,5,7)$ & $(1,1,1)$ & $(1,1,1)$ & $(1,1,1)$ & $(1,3,5)$ & $\left(\frac{1}{8}, \frac{1}{6}, \frac{1}{4}\right)$ & $(2,4,6)$ \\
\hline$e_{9}$ & $\left(\frac{1}{7}, \frac{1}{5}, \frac{1}{3}\right)$ & $(6,8,9)$ & $(4,6,8)$ & $(5,7,9)$ & $\left(\frac{1}{7}, \frac{1}{5}, \frac{1}{3}\right)$ & $\left(\frac{1}{7}, \frac{1}{5}, \frac{1}{3}\right)$ & $\left(\frac{1}{5}, \frac{1}{3}, 1\right)$ & $(4,6,8)$ & $\left(\frac{1}{6}, \frac{1}{4}, \frac{1}{2}\right)$ & $(1,1,1)$ & $(1,1,1)$ & $(1,1,1)$ \\
\hline
\end{tabular}

\subsubsection{Criteria weight}

Table 8 shows the weighted for all main criteria and sub-criteria.

Table 8: Criteria weight

\begin{tabular}{|c|c|c|c|c|c|c|}
\hline M & & $\mathrm{m}_{1}=0.305$ & \multicolumn{2}{|c|}{$\mathrm{m}_{2}=0.411$} & \multicolumn{2}{|c|}{$\mathrm{m}_{3}=0.284$} \\
\hline \multirow{3}{*}{$E$} & $e_{1}$ & 0.22 & $e_{3}$ & 0.309 & $\mathrm{e}_{6}$ & 0.194 \\
\hline & & & $\mathrm{e}_{4}$ & 0.332 & $\mathrm{e}_{7}$ & 0.295 \\
\hline & $\mathrm{e}_{2}$ & 0.78 & $\mathrm{e}_{5}$ & 0.359 & $\begin{array}{l}\mathrm{e}_{8} \\
\mathrm{e}_{9}\end{array}$ & $\begin{array}{c}0.251 \\
0.26\end{array}$ \\
\hline
\end{tabular}

\subsubsection{Alternative decision with respect to sub criteria for each main criteria using FSMmDM}

The evaluation of seven alternatives with respect to sub-criteria of Neighborhood, Property and community by three decision makers are shown in Table 9-11.

Table 9: Evaluation of membership value for fuzzy soft

\begin{tabular}{cccccccc}
\multicolumn{7}{c}{ Matrix by DM } \\
\hline DM1 & $\mathrm{h}_{1}$ & $\mathrm{~h}_{2}$ & $\mathrm{~h}_{3}$ & $\mathrm{~h}_{4}$ & $\mathrm{~h}_{5}$ & $\mathrm{~h}_{6}$ & $\mathrm{~h}_{7}$ \\
\hline $\mathrm{e}_{1}$ & 0.35 & 0.40 & 0.50 & 0.50 & 0.50 & 0.80 & 0.90 \\
$\mathrm{e}_{2}$ & 1.00 & 0.30 & 0.50 & 0.70 & 0.80 & 0.60 & 0.50 \\
$\mathrm{e}_{3}$ & 0.23 & 0.56 & 0.70 & 0.80 & 0.65 & 0.40 & 0.03 \\
$\mathrm{e}_{4}$ & 0.56 & 0.90 & 1.00 & 0.40 & 0.58 & 0.75 & 0.60 \\
$\mathrm{e}_{5}$ & 1.00 & 0.80 & 0.26 & 0.60 & 0.70 & 0.56 & 0.90 \\
$\mathrm{e}_{6}$ & 0.62 & 0.80 & 0.75 & 0.56 & 0.70 & 0.40 & 1.00 \\
$\mathrm{e}_{7}$ & 0.23 & 0.52 & 0.64 & 0.50 & 0.40 & 0.30 & 0.10 \\
$\mathrm{e}_{8}$ & 0.50 & 0.80 & 0.76 & 0.45 & 0.12 & 0.60 & 0.30 \\
$\mathrm{e}_{9}$ & 0.90 & 0.60 & 0.23 & 0.54 & 0.87 & 0.26 & 0.50 \\
\hline
\end{tabular}

- Step B1: Evaluate the membership degree for each alternative with respect to sub-criteria of neighborhood

- Step B2: Use the matrix form to write out the fuzzy soft matrices for alternatives with respect to subcriteria of neighborhood by every decision makers.

Table 10: Evaluation of membership value for fuzzy soft

\begin{tabular}{cccccccc}
\multicolumn{7}{c}{ Matrix by $\mathrm{DM}_{2}$} \\
\hline DM1 & $\mathrm{h}_{1}$ & $\mathrm{~h}_{2}$ & $\mathrm{~h}_{3}$ & $\mathrm{~h}_{4}$ & $\mathrm{~h}_{5}$ & $\mathrm{~h}_{6}$ & $\mathrm{~h}_{7}$ \\
\hline $\mathrm{e}_{1}$ & 0.40 & 0.50 & 0.67 & 0.60 & 0.70 & 0.45 & 0.23 \\
$\mathrm{e}_{2}$ & 0.63 & 0.58 & 0.50 & 0.46 & 0.23 & 0.70 & 0.90 \\
$\mathrm{e}_{3}$ & 0.70 & 0.56 & 0.23 & 0.40 & 0.80 & 1.00 & 0.86 \\
$\mathrm{e}_{4}$ & 0.50 & 0.60 & 0.80 & 0.70 & 0.45 & 0.29 & 0.90 \\
$\mathrm{e}_{5}$ & 1.00 & 0.50 & 0.80 & 0.60 & 0.23 & 0.40 & 0.80 \\
$\mathrm{e}_{6}$ & 0.70 & 0.50 & 0.60 & 0.50 & 0.32 & 0.40 & 0.20 \\
$\mathrm{e}_{7}$ & 0.35 & 0.80 & 070 & 0.60 & 0.50 & 0.32 & 0.24 \\
$\mathrm{e}_{8}$ & 0.60 & 0.50 & 0.45 & 0.65 & 0.63 & 0.23 & 0.75 \\
$\mathrm{e}_{9}$ & 0.70 & 0.50 & 0.65 & 0.40 & 0.53 & 0.62 & 0.23 \\
\hline
\end{tabular}

Table 11: Evaluation of membership value for fuzzy soft

\begin{tabular}{cccccccc}
\multicolumn{7}{c}{ Matrix by DM3 } \\
\hline DM1 & $\mathrm{h}_{1}$ & $\mathrm{~h}_{2}$ & $\mathrm{~h}_{3}$ & $\mathrm{~h}_{4}$ & $\mathrm{~h}_{5}$ & $\mathrm{~h}_{6}$ & $\mathrm{~h}_{7}$ \\
\hline $\mathrm{e}_{1}$ & 0.60 & 0.50 & 0.75 & 0.55 & 0.23 & 0.50 & 0.60 \\
$\mathrm{e}_{2}$ & 0.70 & 0.56 & 0.90 & 0.36 & 0.54 & 0.60 & 0.73 \\
$\mathrm{e}_{3}$ & 0.59 & 0.67 & 0.65 & 0.75 & 0.48 & 0.90 & 0.60 \\
$\mathrm{e}_{4}$ & 0.80 & 0.60 & 0.30 & 0.50 & 0.43 & 0.35 & 0.26 \\
$\mathrm{e}_{5}$ & 0.70 & 0.56 & 0.32 & 0.67 & 0.86 & 0.70 & 0.90 \\
$\mathrm{e}_{6}$ & 1.00 & 0.80 & 0.40 & 0.34 & 0.67 & 0.30 & 0.80 \\
$\mathrm{e}_{7}$ & 0.70 & 0.23 & 0.35 & 0.65 & 0.40 & 0.80 & 0.20 \\
$\mathrm{e}_{8}$ & 0.40 & 0.52 & 0.60 & 0.70 & 0.50 & 0.60 & 0.23 \\
$\mathrm{e}_{9}$ & 0.25 & 0.65 & 0.40 & 0.80 & 0.75 & 0.50 & 0.30 \\
\hline
\end{tabular}


- Step B3: Multiply each parameter with weight of aesthetic and safety for each decision makers. We obtain: $\left[w_{s}\right]=($ Aes $=0.220, S a f=0.780)$, where $w_{s}$ refer to sub-criteria weight with respect to neighborhood

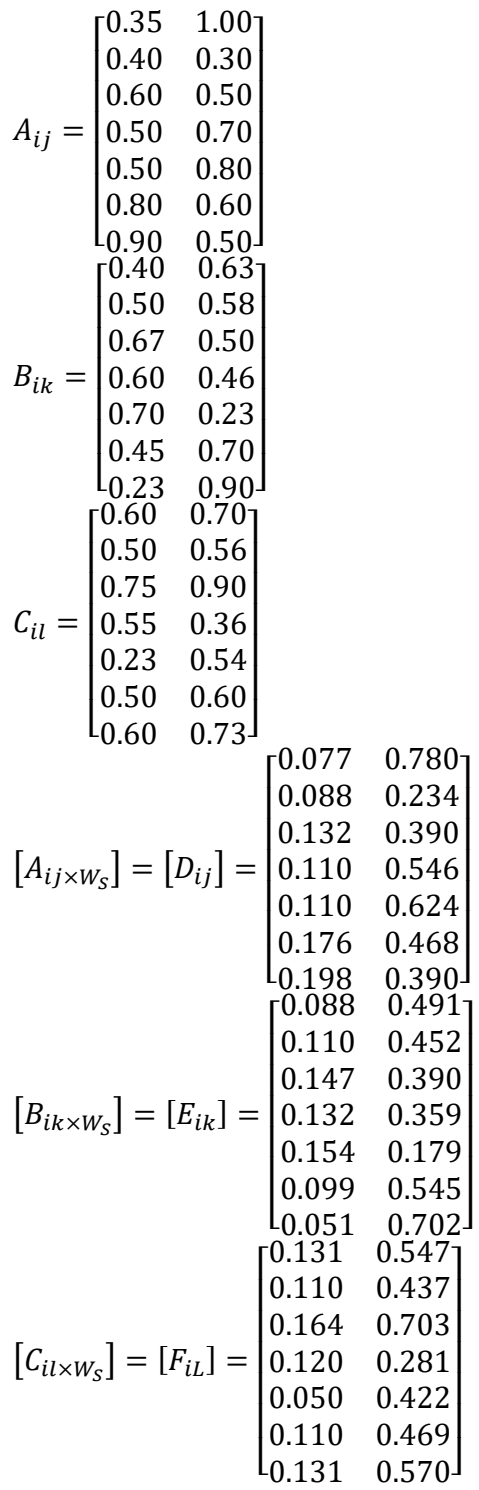

- Step B4: Find the And-Product of fuzzy soft matrices between $\left[D_{i j}\right]$ and $\left[E_{i k}\right]$ is obtained as follows:

$\left[D_{i j} \wedge E_{i k}\right]=\left[\begin{array}{llll}0.077 & 0.077 & 0.088 & 0.491 \\ 0.088 & 0.088 & 0.110 & 0.234 \\ 0.132 & 0.132 & 0.147 & 0.390 \\ 0.110 & 0.110 & 0.132 & 0.359 \\ 0.110 & 0.110 & 0.154 & 0.179 \\ 0.099 & 0.099 & 0.099 & 0.468 \\ 0.051 & 0.198 & 0.051 & 0.390\end{array}\right]$,

which is $7 \mathrm{X} 4$ matrix.

- Step B5: Observe that there are 2 blocks (7x2) elements in the above matrix. For each blocks we choose the minimum for each row. We then obtained minimum between $\left[D_{i j}\right]$ and $\left[E_{i k}\right]$, where

$\left[D_{i j}\right] \wedge\left[E_{i k}\right]=\left[u_{i p}\right]$

$$
\left[u_{i p}\right]=\left[\begin{array}{ll}
0.077 & 0.088 \\
0.088 & 0.110 \\
0.132 & 0.147 \\
0.110 & 0.132 \\
0.110 & 0.154 \\
0.099 & 0.099 \\
0.051 & 0.051
\end{array}\right]
$$

- Step B6: Using And-Product [ $\left.u_{i p}\right] \grave{\mathrm{U}}\left[F_{i l}\right]$ is obtained as:

$$
\left[u_{i p}\right] \wedge\left[F_{i l}\right]=\left[\begin{array}{llll}
0.077 & 0.077 & 0.088 & 0.088 \\
0.088 & 0.088 & 0.110 & 0.110 \\
0.132 & 0.132 & 0.147 & 0.147 \\
0.110 & 0.110 & 0.132 & 0.132 \\
0.056 & 0.110 & 0.056 & 0.154 \\
0.099 & 0.099 & 0.099 & 0.099 \\
0.051 & 0.051 & 0.051 & 0.051
\end{array}\right]
$$

hence $\min$ for the $\left[u_{i p}\right] \wedge\left[F_{i l}\right]=\left[t_{i p}\right]$ is:

$$
\left[t_{i p}\right]=\left[\begin{array}{ll}
0.077 & 0.088 \\
0.088 & 0.110 \\
0.132 & 0.147 \\
0.110 & 0.132 \\
0.056 & 0.056 \\
0.099 & 0.099 \\
0.051 & 0.051
\end{array}\right]
$$

- Step B7: From Step B6, we obtained maximum value in each row of fuzzy soft matrix $\left[t_{i r}\right]$ as:

$$
M m\left(\left[D_{i j}\right] \wedge\left[E_{i k}\right] \wedge\left[F_{i l}\right]\right)=\left[\begin{array}{l}
0.088 \\
0.110 \\
0.147 \\
0.132 \\
0.056 \\
0.099 \\
0.051
\end{array}\right]
$$

where, $h_{3}$ it is decision for alternative for two-subcriteria with respect to neighborhood.

Note: By using the similar steps in procedure 2 from Step B1 until B7, calculate the alternative decision in sub-criteria of property and sub-criteria of community.

By using algorithm of FSMmDM with criteria weight in 3.2.1, calculate the alternative decision of all sub- criteria with respect to their main criteria and the result in Table 12:

a) Alternative decision with respect to "aesthetic $\left(\mathrm{e}_{1}\right)$ " and "safety $\left(\mathrm{e}_{2}\right)$ ", two sub-criteria of Neighborhood

b)Alternative decision with respect to "exterior $\left(\mathrm{e}_{3}\right)$ ", "interior $\left(\mathrm{e}_{4}\right)$ ", and "system ( $\left.\mathrm{e}_{5}\right)$ ", three sub-criteria of Property.

c) Alternative decision with respect to "school $\left(\mathrm{e}_{6}\right)$ ", "government $\left(\mathrm{e}_{7}\right)$ ", "social $\left(\mathrm{e}_{8}\right)$ " and "entertainment(e9)"four sub-criteria of Community.

\subsubsection{Overall priority vector}

The overall priority vector can be obtained by multiplying priority vector for the house selection by the priority vector of the criteria shows in Table 13. 
Table 12: The overall priority vector of the alternatives with respect to the criteria

\begin{tabular}{cccc}
\hline & $\mathrm{m}_{1}$ & $\mathrm{~m}_{2}$ & $\mathrm{~m}_{3}$ \\
\hline Weight & 0.305 & 0.411 & 0.284 \\
$\mathrm{~h}_{1}$ & 0.088 & 0.166 & 0.067 \\
$\mathrm{~h}_{2}$ & 0.110 & 0.173 & 0.067 \\
$\mathrm{~h}_{3}$ & 0.147 & 0.071 & 0.078 \\
$\mathrm{~h}_{4}$ & 0.132 & 0.124 & 0.066 \\
$\mathrm{~h}_{5}$ & 0.056 & 0.083 & 0.062 \\
$\mathrm{~h}_{6}$ & 0.099 & 0.096 & 0.058 \\
$\mathrm{~h}_{7}$ & 0.051 & 0.086 & 0.039 \\
\hline
\end{tabular}

Table 13: Overall priority vector

\begin{tabular}{ccccc}
\hline ALT & Neighbor-hood & Property & Community & Overall \\
\cline { 1 - 4 } & 0.305 & 0.411 & 0.284 & Priority \\
$\mathrm{h}_{1}$ & 0.088 & 0.166 & 0.067 & 0.114 \\
$\mathrm{~h}_{2}$ & 0.110 & 0.173 & 0.067 & 0.124 \\
$\mathrm{~h}_{3}$ & 0.147 & 0.071 & 0.078 & 0.096 \\
$\mathrm{~h}_{4}$ & 0.132 & 0.124 & 0.066 & 0.110 \\
$\mathrm{~h}_{5}$ & 0.056 & 0.083 & 0.062 & 0.069 \\
$\mathrm{~h}_{6}$ & 0.099 & 0.096 & 0.058 & 0.086 \\
$\mathrm{~h}_{7}$ & 0.051 & 0.086 & 0.039 & 0.062 \\
\hline
\end{tabular}

\section{Example:}

$0.088(0.305)+0.166(0.411)+0.067(0.284)=0.114$

It is clear that the maximum score among seven alternatives is 0.124 , scored by $h_{2}$ and the decision is in favor of selecting $h_{2}$

\section{Conclusion}

In this paper we have shown that Fuzzy soft matrix hierarchical structure can be effectively used in solving group decision making problems that consider all level in the hierarchical structure. We implemented the Lambda max method introduced by Csutora and Buckley (2001) and fuzzy soft maxmin decision making (FSMmDM) method introduced by Çağman and Enginoğlu (2010a; 2010b) that satisfied the associative law. The result shows that the maximum value of overall priority vector for the seven of house selection is house 2 , hence the decision maker will be choose $h_{2}$

This method will be applied to other multicriteria decision making problems in uncertainties or vague data. At the same time determination of criteria weight can be determine by using other AHP method such as Fuzzy AHP or extent analysis.

\section{References}

Çağman N and Enginoğlu S (2010a). Soft set theory and uni-int decision making. European Journal of Operational Research, 207(2): 848-855.
Çağman N and Enginoğlu S (2010b). Soft matrix theory and its decision making. Computers and Mathematics with Applications, 59(10): 3308-3314.

Çağman N and Enginoğlu S (2012). Fuzzy soft matrix theory and its application in decision making. Iranian Journal of Fuzzy Systems, 9(1): 109-119.

Carlsson C and Fullér R (1996). Fuzzy multiple criteria decision making: Recent developments. Fuzzy Sets and Systems, 78(2): 139-153.

Celik Y and Celik IA (2016). Framework for medical diagnosis via fuzzy soft matrices. New Trend in Mathematical Sciences, 4(2): 248-256.

Chetia B and Das PK (2010). An application of interval-valued fuzzy soft. International Journal of Contemporary Mathematical Sciences, 5(38): 1887-1894.

Csutora R and Buckley JJ (2001). Fuzzy hierarchical analysis: the Lambda-Max method. Fuzzy Sets and Systems, 120(2): 181195.

Hambali A, Sapuan SM, Ismail N, and Nukman Y (2009). Application of analytical hierarchy process in the design concept selection of automotive composite bumper beam during the conceptual design stage. Scientific Research and Essays, 4(4): 198-211.

Herawan T and Deris MM (2010). Soft decision making for patients suspected influenza. In the International Conference on Computational Science and Its Applications, Springer, Berlin, Heidelberg: 405-418. https://doi.org/10.1007/978-3642-12179-1_34

Maji PK, Biswas R, and Roy AR (2001). Intuitionistic fuzzy soft sets. Journal of Fuzzy Mathematics, 9(3), 589-602.

Maji PK, Roy AR, and Biswas R (2002). An application of soft sets in a decision making problem. Computers and Mathematics with Applications, 44(8-9): 1077-1083.

Molodtsov D (1999). Soft set theory-first results. Computers and Mathematics with Applications, 37(4-5): 19-31.

Razak S and Mohamad D (2012). Aplikasi Matrik Lembut dalam Masalah Pembuatan Keputusan Secara Berkumpulan [An Application of Soft Matrices in Group Decision Making Problems]. Menemui Matematik [Discovering Mathematics], 34(1): 33-39.

Roy AR and Maji PK (2007). A fuzzy soft set theoretic approach to decision making problems. Journal of Computational and Applied Mathematics, 203(2): 412-418.

Wei YANG (2010). Fuzzy soft matrix and its lattice structure [J]. Journal of Liaoning Technical University (Natural Science), Jiangxi University of Technology, Nanchang, China. Available online at: http://en.cnki.com.cn/Article_en/CJFDTOTALFXKY201005006.htm

Yang Y and Ji C (2011). Fuzzy soft matrices and their applications. In the International Conference on Artificial Intelligence and Computational Intelligence, Springer, Berlin, Heidelberg: 618627. https://doi.org/10.1007/978-3-642-23881-9_79 